\title{
Efeito de substratos, luz e sobreposição de papel de filtro na esporulação de Corynespora cassiicola
}

\author{
Márcia Muliterno de Melo ${ }^{1} \&$ Erlei Melo Reis ${ }^{1,2}$
}

${ }^{1}$ Faculdade de Agronomia e Medicina Veterinária, Departamento de Ftossanidade Universidade de Passo Fundo-, UPF, 99001, Passo Fundo, RS, Brasil. Bolsista CAPES. ${ }^{2}$ Bolsista do CNPq. Este trabalho faz parte da dissertação de mestrado de Márcia Muliterno de Melo Autor para correspondência: Erlei Melo Reis (erleireis@tpo.com.br) Data de chegada: 27/07/2009. Aceito para publicação em: 10/06/2010.

1668

\section{RESUMO}

Melo, M. M. \& Reis, E. M. Efeito de substratos, luz e sobreposição de papel de filtro na esporulação de Corynespora cassiicola. Summa Phytopathologica, v.36, n.3, p.251-253, 2010.

O experimento foi realizado no Laboratório de Fitopatologia Micologia, na Faculdade de Agronomia e Medicina Veterinária da Universidade de Passo Fundo, com a finalidade de avaliar a esporulação de Corynespora cassiicola em diferentes substratos. Para isso foram usadas placas de petri com seis diferentes meio de cultura - Batata Dextrose Ágar (BDA), Solução Czapek Ágar, Alimento infantil, Malte Ágar, Farinha de aveia e suco V8 Ágar e quatro combinações (com luz alternada e sobreposição de papel filtro, com luz alternada e sem sobreposição de papel filtro, sem luz com sobreposição de papel filtro e sem luz e sem sobreposição de papel filtro). O delineamento experimental usado foi fatorial triplo (substrato, luz/escuro, com ou sem sobreposição de papel filtro). Na avaliação de esporulação do fungo, foram cortados dois discos de $0,241 \mathrm{~cm}^{2}$ em cada placa dos diferentes substratos e colocados em tubos de ensaio contendo $10 \mathrm{~mL}$ de água destilada. Esses tubos foram agitados e de cada um foram retiradas três alíquotas de $10 \mathrm{~mL}$ para contagem de conídios no microscópio óptico. Os dados foram transformados em número de esporos.cm². A maior esporulação do fungo foi obtida com o substrato Solução Czapek-Ágar, com fotoperíodo de 12 horas e sobreposição de papel filtro.

Palavras-chave adicionais: Produção de inóculo, meio de cultura, regime de luz

\section{ABSTRACT}

Melo, M. M. \& Reis, E. M. Effect of substrates, light and filter paper on Corynespora cassiicola sporulation. Summa Phytopathologica, v.36, n.3, p.251-253, 2010.

This experiment was carried out in the Laboratory of Phytopathology - Mycology - School of Agronomy and Veterinary Medicine, Passo Fundo University, in order to evaluate Corynespora cassiicola sporulation on different substrates. Thus the used Petri plates contained six different culture media - Potato Dextrose Agar (PDA), Czapek Solution Agar, infant food, Malt Agar, Oatmeal Agar, and V8 juice agar, besides four combinations (with both light and filter paper, with light and without filter paper, with filter paper and without light, and without light and without filter paper). Experimental design was triple factorial (substrate, light / dark, with or without filter paper). In the fungus sporulation assessment, two disks $(0241 \mathrm{~cm}$ $\left.{ }^{2}\right)$ were cut from each plate of the different substrates and transferred to test tubes containing $10 \mathrm{~mL}$ distilled water. These tubes were shaken: then, three $10 \mathrm{~mL}$ - aliquots were removed for conidia counting under optical microscope, The obtained data were converted into number of spores. $\mathrm{cm}^{2}$. The highest fungus sporulation was obtained with the substrate Czapek Solution Agar under 12h-light photoperiod and filter paper overlapping.

Keywords: Inoculum production, culture medium, photoperiod

Atualmente o Brasil é o segundo maior produtor mundial de soja, sendo superado apenas pelos Estado Unidos. A produção brasileira de soja somou, na safra 2007/2008, 60 milhões de toneladas, superando em 2,8\% a do ano anterior. A área colhida foi de 21 mil ha. Na média nacional, o rendimento da soja foi de 2,8 kg.ha-1, 18,3\% maior que os 2,3 kg.ha-1 registrados em 2006/2007, em razão das condições climáticas mais favoráveis e da priorização do plantio pelos produtores nas áreas mais aptas ao cultivo. Os principais estados produtores no Brasil são Mato Grosso, Paraná e Rio Grande do Sul, (2).

A mancha-alvo, causada por Corynespora casssiicola (Berk \& Curt.) Wei, é encontrada em todas as áreas produtoras de soja do Brasil. É uma doença de grande importância na Região do Cerrado, onde ocorre com maior freqüência. Ocorrência da doença tem sido observada esporadicamente, desde as zonas mais frias do Sul às chapadas dos Cerrados, (3).

Conforme Seaman et al. (7), os conídios do fungo são produzidos facilmente sob uma vasta gama de temperatura em meio de cultura BDA ou Czapek Agar, produzindo tubos germinativos em uma ou em ambas extremidades.

Almeida \& Yamashita (1) observaram o crescimento e a esporulação do fungo em diferentes meios de cultura, e concluíram que nos meios suco V-8 e alimento infantil o fungo obteve melhor esporulação.

O objetivo desse trabalho foi quantificar a esporulação de $C$. cassiicola em diferentes substratos, contendo ou não sobreposição de papel filtro, submetidos a luz alternada ou escuro, através da contagem do número de esporos.cm².

O presente trabalho foi realizado no Laboratório de FitopatologiaMicologia e em câmara de crescimento, da Faculdade de Agronomia e 
Medicina Veterinária da Universidade de Passo Fundo, no período de abril de 2008.

O delineamento experimental usado foi fatorial triplo $6 \times 2 \times 2$ (substratos x luz/escuro x com/sem papel filtro), com cinco repetições, distribuídas ao acaso.

Os substratos usados foram: 1) Solução Czapek Ágar- $3 \mathrm{~g} \mathrm{NaNO}_{3}$, $1 \mathrm{~g} \mathrm{~K}_{2} \mathrm{HPO}_{4}$, 0,5 $\mathrm{g} \mathrm{MgSO}_{4}, 0,5 \mathrm{~g} \mathrm{KCl}, 0,01 \mathrm{~g} \mathrm{FeSO}_{4}, 30 \mathrm{~g}$ sacarose, $15 \mathrm{~g}$ ágar, 0,2g estreptomicina, $1 \mathrm{~L}$ água destilada, (8); 2) Farinha de aveia Ágar- 72,5g farinha de aveia e ágar, 0,2g estreptomicina, 1L água destilada (meio de cultura pronto oatmeal, produto de SIGMA); 3) Malte Ágar- $20 \mathrm{~g}$ extrato malte, $1 \mathrm{~g}$ peptona, $20 \mathrm{~g}$ dextrose, $20 \mathrm{~g}$ ágar, 0,2g estreptomicina, 1L água destilada, (8); 4) Suco V8 Ágar- $200 \mathrm{ml}$ suco V-8 (Produto da Campbell Soup Co., contendo suco de tomate, mistura de sucos vegetais: cenoura, aipo, beterraba, salsa, alface, agrião e espinafre, sal, antioxidante, ácido ascórbico, acidulante acido cítrico e aromatizante.), $3 \mathrm{~g} \mathrm{CaCO}_{3}, 15 \mathrm{~g}$ ágar, 0,2 estreptomicina, $1 \mathrm{~L}$ água destilada, (8); 5) Alimento infantil- 10g alimento infantil (Produto da Nestlé Brasil Ltda, contendo água, cenoura, batata, feijão, cebola, chuchu, óleo de milho, polpa de tomate, leite desnatado, soro de leite, óleo de canola, amido, farinha de arroz, beterraba, sal), 15g ágar, 0,2g estreptomicina, 1L água destilada, (1) e 6) BDA- 200g de batatas, $17 \mathrm{~g}$ dextrose, 15g ágar, 0,2g estreptomicina, 1L água destilada, (8).

Primeiramente foram preparadas 20 placas de Petri com cada meio de cultura, sendo que em 10 placas, foi colocado uma folha de papel filtro, do tipo germitest, sobre o substrato. Nas 10 placas de Petri restantes não foi adicionado papel filtro.

Com auxílio de pincel de pelo de camelo número 20, foi realizada a remoção dos esporos de seis placas de Petri, contendo colônias puras de C. cassiicola, produzidas em BDA para um erlenmayer contendo $300 \mathrm{~mL}$ de água destilada e esterilizada e uma gota de espalhante adesivo, Tween 20 (polioxietilenosorbitano). Dessa suspensão, foi pipetado $10 \mathrm{~mL}$ e preparada uma lâmina (câmara de Neubauer) para contar o número de conídios existente em gota de volume conhecido, esse procedimento foi realizado 4 vezes, com a finalidade de se obter o número de conídios. $\mathrm{mL}^{-1}$ de água.

Em placas de Petri, contendo os substratos, com auxílio de micropipetador foi colocado $1 \mathrm{~mL}$ dessa suspensão de conídios por placa.

Os tratamentos com luz, com e sem sobreposição de papel filtro no substrato foram distribuídos ao acaso, em câmara de crescimento, com lâmpadas OSRAM Universal, 40 watts, fotoperíodo 12 horas a $25^{\circ} \pm 2{ }^{\circ} \mathrm{C}$. As placas de tratamentos escuro, com e sem sobreposição de papel filtro no substrato, foram envolvidas em papel alumínio e distribuídas ao acaso, em um recepiente fechado, dentro da câmara de crescimento para terem a mesma temperatura dos outros tratamentos.

As placas permaneceram na câmara de crescimento por 15 dias.

Em tubos de ensaio, contendo $10 \mathrm{~mL}$ de água destilada e esterilizada com espalhante adesivo (Tween 20), foram adicionados dois discos recortados do substrato, de área $0.241 \mathrm{~cm}^{2}$, com micélio do fungo, para quantificar a esporulação de $C$. cassiicola. Os tubos foram agitados em agitador manual (vortex) e retiradas três alíquotas de $10 \mathrm{~mL}$, as quais foram depositadas em lâminas microscópias e, por varredura sob microscópio óptico, foram contados conídios existentes.

Os dados foram transformados em número de esporos. $\mathrm{cm}^{2} \mathrm{e}$ foram submetidos à análise da variância e ao teste de comparação de médias, Tukey $5 \%$.

A maior esporulação ocorreu no substrato Solução Czapekágar, com fotoperíodo de 12 horas de luz, e papel filtro sobreposto ao meio de cultura, diferindo significativamente dos demais tratamentos ( Tabela 1).

Todos os outros substratos testados tiveram esporulação no tratamento com fotoperíodo de 12 horas e papel filtro, tendo diferença significativa dos tratamentos que permaneceram no escuro.

Também ocorreu boa esporulação dos substratos BDA e Malte ágar. Suco V-8 ágar, Farinha de aveia e alimento infantil tiveram a menor esporulação do inóculo, e não diferiam entre si.

Para o tratamento com luz e sem sobreposição de papel filtro no meio de solução Czapek-ágar diferiu significativamente de todos os outros meios usados. Esses resultados são semelhantes aos obtidos por Olive et al. (4), onde os autores obtiveram excelente esporulação do fungo nos meios solução Czapek Ágar e BDA. No entanto, esses resultados diferem dos obtidos por Almeida \& Yamashita (1), onde as melhores esporulações do fungo ocorreram nos meios suco V8 Ágar e alimento infantil. Essa diferença de esporulação no substrato alimento infantil pode estar relacionada a composição do alimento usado para fazer o substrato, pois Almeida \& Yamashita (1) usaram alimento infantil da marca Gerber, enquanto nesse trabalho o alimento infantil usado foi da marca Nestlé. Tal diferença de esporulação também pode ser explicada pelo fato de serem isolados diferentes de $C$. cassiicola.

Para os tratamentos realizados no escuro, independente da sobreposição de papel filtro, a solução Czapek-ágar e suco V8-ágar resultaram nas menores esporulações do fungo. No tratamento escuro com papel a melhor esporulação foi em BDA e no tratamento escuro

Tabela 1. Influência de substratos sobre a esporulação de Corynespora cassiicola $\left(\mathrm{n}^{\circ}\right.$ conídios.cm²), na presença e ausência da luz, e, com e sem sobreposição de papel filtro

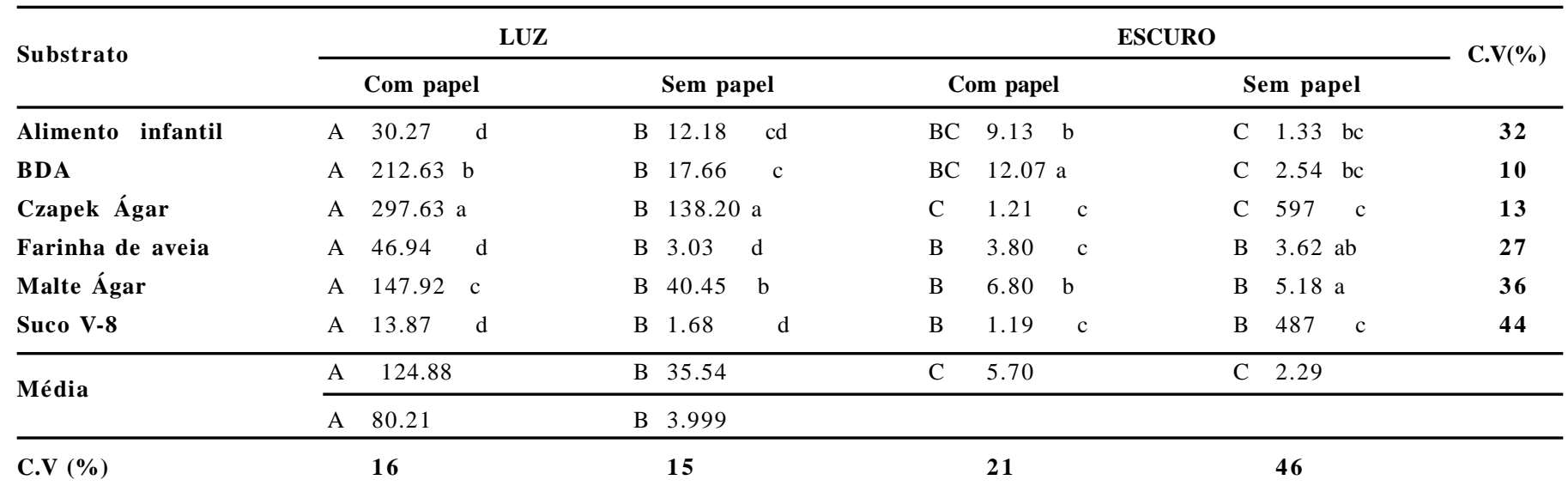

Médias antecedidas da mesma letra maiúscula na linha e seguidas de mesma letra minúscula na coluna, não diferem entre si pelo teste de Tukey a 5 \% de probabilidade. 
sem papel foi em malte ágar.

Em todos os substratos testados a presença de fotoperíodo de 12horas favoreceu a esporulação quando em comparação com dados obtidos na ausência de luz. Esses dados assemelham-se aos obtidos por Almeida \& Yamashita (1). De acordo com Onesirosan et al. (5), a presença de luz favorece a esporulação desse fungo, embora certos isolados testados tenham esporulado mais que outros.

A presença de papel filtro promoveu maior esporulação em todos os tratamentos. Conforme Reis (6), o aumento da superfície de contato, conferida pelo papel de filtro, pode ser responsável pela maior esporulação.

O melhor substrato para esporulação de $C$. cassiicola foi a solução Czapek Ágar, na presença de fotoperíodo de 12 horas e com sobreposição de papel filtro ao meio.

\section{REFERENCIAS BIBLIOGRÁFICAS}

1. Almeida, A.M.R.; Yamashita, J. Crescimento e esporulação de Corynespora cassiicola (Berk. \& Curt.) Wei em diferentes meio de cultura. Fitopatologia Brasileira, Brasília, v.1, p.
$203-206,1976$.

2. Companhia Nacional de Abastecimento (Conab). Acompanhamento da safra brasileira de grãos 2007/2008. Disponível em: <ww w.conab.gov.br/conabweb/download/safra/ 12_levantamento_set2008.pdf >. Acesso em: 05 set.2008.

3. Empresa Brasileira de Pesquisa Agropecuária (EMBRAPA). Sistema de produção. Tecnologias de Produção de Soja Região Central do Brasil. Versão eletrônica. Embrapa. 2003.

4. Olive, L.S.; Bain, D.C.; Lefebvre, C.L. A leaf spot of cowpea and soybean caused by undescribed species of Helminthosporium. Phytopathology, St. Paul, v.35, p.822-831, 1945.

5. Onesiran, P.; Arny, D.; Durbin, R.D. Increasing sporulation of Corynespora cassiicola. Mycophathologia, Medison v. 55, p. $121-123,1975$

6. Reis, E.M. Efeito da concentração de inóculo de Colletotrichum dematium $f$. truncata (Schw.) Von ARX na reação de variedades de soja (Glycine max (L.) Merr. 1973 Dissertação (Mestrado em Agronomia/ Fitopatologia) - Escola Superior de Agricultura Luiz de Queiroz, Universidade de São Paulo, Piracicaba.

7. Seaman, W.L.; Shoemaker, R.A.; Peterson, E.A. Pathogenicity of Corynespora cassiicola on soybean. Canadian Journal Botany, v. 43, p. 1461 - 1469, 1965

8. Tuite, J. Plant pathological methods - fungi and bacterial. Minneapolis: Burgess, 1969. 